\title{
Merging host-guest chemistry and organocatalysis for the chemical valorization of $\mathrm{CO}_{2}$
}

\author{
Anaïs Mirabaud ${ }^{\mathrm{a}, \mathrm{b}}$, Jean-Christophe Mulatier ${ }^{\mathrm{a}}$, Alexandre Martinez ${ }^{\mathrm{a}, \mathrm{c}}$, \\ Jean-Pierre Dutasta ${ }^{\mathrm{a}, *}$, Véronique Dufaud ${ }^{\mathrm{b}, *}$ \\ a Laboratoire de Chimie, École Normale Supérieure de Lyon, CNRS, Université Claude Bernard Lyon 1, 46 allée d'Italie, F-69364 Lyon, France \\ ${ }^{\mathrm{b}}$ Laboratoire de Chimie, Catalyse, Polymères, Procédés (C2P2), CNRS, Université Claude Bernard Lyon 1, CPE Lyon, 43 Bd du 11 novembre 1918, F-69616 \\ Villeurbanne cedex, France \\ ' Aix Marseille Université, Centrale Marseille, CNRS, iSm2 UMR 7313, F-13397 Marseille, France
}

\begin{abstract}
A B S T R A C T
The use of tri- and tetraphosphonate cavitand hosts in conjunction with tetrabutylammonium halide catalysts led to improved activity in the coupling of 1,2-epoxyhexane and $\mathrm{CO}_{2}$. Catalytic efficiency of the supramolecular assembly strongly relies on both the structural features and binding properties of the cavitand host. Tetraphosphonate cavitand host (4iPO 1) was shown to impact more markedly $n$ $\mathrm{Bu}_{4} \mathrm{NCl}$ reactivity than triphosphonate counterpart ( $3 \mathrm{iPO} 3$ ) due to its greater binding strength toward the ammonium cation as evidenced by titration experiments. The participation of acidic functional groups within the cavitand structure to activity enhancement was also clearly demonstrated. The best result was obtained with $n$ - $\mathrm{Bu}_{4} \mathrm{NI} / 3 \mathrm{iPO} 2$ supramolecular assembly affording hexene carbonate in quantitative yield after $18 \mathrm{~h}$ of reaction. The improved performance observed with the cavitand 3iPO 2 relies on a double activation of both the nucleophile (halide) through efficient encapsulation of the ammonium cation and the substrate (epoxide) through hydrogen bonding.
\end{abstract}

\section{Introduction}

The utilization of carbon dioxide $\left(\mathrm{CO}_{2}\right)$ as a key component in organic transformations has recently drawn much attention as a greener alternative to fossil fuel based resources [1-3]. $\mathrm{CO}_{2}$ is cheap, abundant and non-toxic and the development of synthetic methodologies that efficiently incorporate $\mathrm{CO}_{2}$ into one or several steps to produce value-added molecules represents a significant gain in atom economy, process safety and energy investment over current technology [4]. The coupling of $\mathrm{CO}_{2}$ with epoxides to produce five-membered cyclic carbonates is a powerful candidate for $\mathrm{CO}_{2}$ chemical fixation because of the high atom economy of the reaction [5-8] and for the many applications of carbonate compounds as building block or additives [9-12]. Numerous homogeneous and heterogeneous catalysts have been developed for this reaction among which metal-based systems occupy a prominent position $[13,14]$. In particular, transition metal complexes derived from the porphyrin [15] or salen/salphen scaffolds [16],

E-mail addresses: jean-pierre.dutasta@ens-lyon.fr (J.-P. Dutasta), veronique.dufaud@univ-lyon1.fr (V. Dufaud). when used in conjunction with onium salts, generally showed great performance in terms of turnover numbers and initial turnover frequencies achieving in some cases up to $12000 \mathrm{~h}^{-1}$ [17-20]. In these systems, the cooperative action of both the Lewis acid (e.g. Al, $\mathrm{Zn}, \mathrm{Mn}, \mathrm{Cr}$, Co amongst other) and the nucleophile (e.g. the counteranion of the onium salt) at the epoxide through respectively oxygen atom coordination and nucleophilic ring-opening proved to be optimal for catalysis. However, for sustainability considerations and to respond to increasingly stringent regulatory issues concerning metal contamination, metal-free mediated $\mathrm{CO}_{2}$ fixation methodologies have recently emerged as a proficient alternative. Besides commercially available quaternary ammonium and phosphonium salts [21], several other structural types have been shown to enable $\mathrm{CO}_{2}$ fixation into cyclic carbonates, including ionic liquids [22,23], betain-based structures [24] and organic bases [25], although each requires elevated temperatures and pressures for the reaction to proceed. Significant improvements in catalyst efficiency have recently been achieved from organic structures bearing potential H-bonding sites to synergistically activate the substrate and/or stabilize reaction intermediates [26-28]. For example, Kleij and coworkers have shown that the combination of polyphenolic-based compounds such as catechol and/or pyrogallol with $n-\mathrm{Bu}_{4} \mathrm{NI}$ led to a very efficient catalytic system able to operate under relatively mild 
reaction conditions $\left(25-45^{\circ} \mathrm{C}, \mathrm{PCO}_{2}=10 \mathrm{bar}, 2-5 \mathrm{~mol} \%\right.$ catalyst $)$ [8]. In our own studies, we have demonstrated that azaphosphatranes (AZAP), the acidic conjugates of Verkade's superbases, whether acting alone [29] or encapsulated in a hemicryptophane supramolecular cavity [30], could also function as efficient singlecomponent catalysts at atmospheric pressure of $\mathrm{CO}_{2}$ and under mild conditions $\left(80-100^{\circ} \mathrm{C}, 0.1 \mathrm{~mol} \%\right.$ catalyst) through dual activation of both epoxide and $\mathrm{CO}_{2}[31]$.

In our current studies, another approach based on host-guest chemistry has recently been developed to improve organocatalyst efficiency. By combining ammonium halide salts and specifically designed ammonium cavitand receptors, efficient incorporation of $\mathrm{CO}_{2}$ into cyclic carbonates was successfully achieved under mild conditions, at atmospheric pressure of $\mathrm{CO}_{2}$ and moderate temperature $\left(100^{\circ} \mathrm{C}\right)[32$ ]. In this approach, enhancement is obtained by increasing the nucleophilicity of the halide rather than epoxide activation and relies on the strong binding properties of tetraphosphonate cavitand hosts towards ammonium cations. The most dramatic effect of such host-guest approach was demonstrated with tetramethylammonium derivatives, which, when used alone, are completely inactive even under harsher reaction conditions. Among the $\mathrm{Me}_{4} \mathrm{NX}$ series, the $\mathrm{Me}_{4} \mathrm{NI} /$ cavitand inclusion complex showed the best performance, as expected given that the iodide anion is both a good nucleophile and an excellent leaving group, achieving up to $92 \%$ yield in styrene carbonate after $24 \mathrm{~h}$ of reaction and full conversion at $48 \mathrm{~h}$.

Herein, we wish to further explore the potential of integrating this host-guest chemistry approach in the field of $\mathrm{CO}_{2}$ chemical valorization. The study focusses on two key factors and their effects, individually and in concert, on the catalytic reaction: the binding properties of different cavitand structures with respect to the tetrabutylammonium cation and the role of acidic functional groups on certain cavitand species. The binding properties will be directly observed by titration as followed with ${ }^{31} \mathrm{P}$ NMR, and inferred from the effects of this binding on catalytic activity (structure-activity relationships). Clear evidence for the participation of acidic functional groups within the cavitand structure will also be presented as it leads to the highest performing ammonium halide based catalyst available.

\section{Experimental}

\subsection{General}

Commercial reagents were purchased from Aldrich Chemical and used without further purification unless otherwise noted. Solvents were dried using standard methods and stored over activated $4 \AA$ A molecular sieves. $\mathrm{CO}_{2}$ of a purity of $99.99 \%$ was commercially obtained and used without further purification.

${ }^{1} \mathrm{H}$ and ${ }^{31} \mathrm{P}$ NMR spectra for titration experiments were recorded on a Bruker AC-500 spectrometer as well as liquid NMR spectra of molecular compounds and referenced as follows: ${ }^{1} \mathrm{H}(500.1 \mathrm{MHz})$ and ${ }^{13} \mathrm{C}(125.7 \mathrm{MHz})$ chemical shifts were measured relative to residual ${ }^{1} \mathrm{H}$ or ${ }^{13} \mathrm{C}$ resonances in $\mathrm{CDCl}_{3}$ and ${ }^{31} \mathrm{P}(202.4 \mathrm{MHz})$ chemical shifts were referenced to external $85 \% \mathrm{H}_{3} \mathrm{PO}_{4}$ at $\delta=0.00 \mathrm{ppm}$. Data are reported as follows: chemical shift, number of equivalent nuclei, multiplicity ( $\mathrm{s}=$ singlet, $\mathrm{d}=$ doublet, $\mathrm{t}=$ triplet, $\mathrm{q}=$ quartet, sex = sextuplet, $m=$ multiplet $)$, coupling constant $(J$ in $\mathrm{Hz}$ ), assignment. During catalytic runs, yields were estimated by ${ }^{1} \mathrm{H}$ NMR with a Bruker Avance 300 spectrometer at $300.1 \mathrm{MHz}$. Mass spectral analyses were performed on a Nermag R10-10C for exact mass. Silica gel used for column chromatography was Merk 60 Kieselgel $(0.040-0.063 \mathrm{~mm}) .4 i \mathrm{PO} 1$ and 3iPO 2 hosts were synthesized following previous literature procedures [33,34]. (Scheme S1 in Supporting information)

Cavitand 3iPO $2(0.20 \mathrm{~g}, 0.14 \mathrm{mmol})$ was dissolved in dry DMF $(10 \mathrm{~mL})$ under argon. Then, $\mathrm{K}_{2} \mathrm{CO}_{3}(94.0 \mathrm{mg}, 0.68 \mathrm{mmol})$ and propargyl bromide $(35.4 \mathrm{mg}, 0.30 \mathrm{mmol})$ were added. After refluxing for $36 \mathrm{~h}$, the solution was allowed to reach room temperature and the organic layers were extracted with $\mathrm{CH}_{2} \mathrm{Cl}_{2}(2 \times 10 \mathrm{~mL})$ then washed with brine $(2 \times 10 \mathrm{~mL})$ before being dried over $\mathrm{Na}_{2} \mathrm{SO}_{4}$. After filtration, the solvent was removed under reduced pressure and an orange residue was obtained. The crude product was purified by column chromatography $\left(\mathrm{CH}_{2} \mathrm{Cl}_{2}\right.$ /acetone 80:20) affording host 3 iPO 3 as a white powder (165 mg, 76\%). ${ }^{1} \mathrm{H},{ }^{13} \mathrm{C}$ and ${ }^{31} \mathrm{P}$ NMR spectra are provided in Supporting information (Figs. S1-S3) along with nuclei numbering and assignment.

$\delta_{\mathrm{H}}\left(500.1 \mathrm{MHz} ; \mathrm{CDCl}_{3}\right)$ 8.00-8.13 $\left(6 \mathrm{H}, \mathrm{m}, \mathrm{H}_{4}\right), 7.47-7.67(9 \mathrm{H}$, m, $\left.\mathrm{H}_{5}, \mathrm{H}_{6}\right), 7.37\left(2 \mathrm{H}, \mathrm{s}, \mathrm{H}_{2 \mathrm{~b}}\right), 7.24\left(2 \mathrm{H}, \mathrm{s}, \mathrm{H}_{2 \mathrm{a}}\right), 7.05\left(2 \mathrm{H}, \mathrm{s}, \mathrm{H}_{1 \mathrm{~b}}\right)$, $6.69\left(2 \mathrm{H}, \mathrm{s}, \mathrm{H}_{1 \mathrm{a}}\right), 5.07\left(1 \mathrm{H}, \mathrm{t},{ }^{3} \mathrm{~J}=8.2, \mathrm{H}_{3 \mathrm{c}}\right), 4.76\left(3 \mathrm{H}, \mathrm{m}, \mathrm{H}_{3 \mathrm{a}}, \mathrm{H}_{3 \mathrm{~b}}\right)$, $4.73\left(1 \mathrm{H}, \mathrm{dd},{ }^{3} J=2.4,{ }^{1} \mathrm{~J}=15.6, \mathrm{H}_{7}\right), 4.57\left(1 \mathrm{H}, \mathrm{dd},{ }^{3} \mathrm{~J}=2.4,{ }^{1} J=15.6\right.$, $\left.\mathrm{H}_{7}\right), 2.48\left(2 \mathrm{H}, \mathrm{t},{ }^{3} \mathrm{~J}=2.4, \mathrm{C}=\mathrm{CH}\right), 2.32\left(6 \mathrm{H}, \mathrm{m}, \mathrm{CH}_{2}\left(\mathrm{CH}_{2}\right)_{9} \mathrm{CH}_{3}\right), 2.06$ $\left(2 \mathrm{H}, \mathrm{m}, \mathrm{CH}_{2}\left(\mathrm{CH}_{2}\right)_{9} \mathrm{CH}_{3}\right), 1.19-1.55\left(72 \mathrm{H}, \mathrm{m}, \mathrm{CH}_{2}\left(\mathrm{CH}_{2}\right)_{9} \mathrm{CH}_{3}\right), 0.89$ $\left(12 \mathrm{H}, \mathrm{m}, \mathrm{CH}_{2}\left(\mathrm{CH}_{2}\right)_{9} \mathrm{CH}_{3}\right) . \delta_{\mathrm{C}}\left(125.7 \mathrm{MHz} ; \mathrm{CDCl}_{3}\right) 154.89,146.53$, $146.12,145.85,135.47,134.61,133.26,131.96,131.74,131.66$, $128.62,128.49,128.30,126.57,126.31,124.05,121.71,117.45$, $106.88,79.16,75.33,56.24,36.00,35.60,33.83,31.97,31.15,29.75$, 29.68, 29.43, 28.04, 27.95, 22.71, 14.12. $\delta_{\mathrm{P}}\left(202.4 \mathrm{MHz} ; \mathrm{CDCl}_{3}\right)$ 8.79, 9.14 (2P). ESI-MS $m / z$ obsd $1547.84[\mathrm{M}-\mathrm{H}]^{+}$, calcd 1547.93 for $\mathrm{C}_{96} \mathrm{H}_{125} \mathrm{O}_{11} \mathrm{P}_{3}$.

\subsection{Titration experiments}

Determination of the association constants $(\mathrm{Ka})$ between tetrabutylammonium cation and 4iPO 1 and 3iPO 2 hosts was obtained from titration experiments monitored by ${ }^{31} \mathrm{P}$ NMR (respectively Figs. S4 and S5, Supporting information). Typically, a solution of cavitand host $\left(6 \mathrm{mM}\right.$ in $\left.\mathrm{CDCl}_{3} / \mathrm{MeOD} 8: 2,500 \mu \mathrm{L}\right)$ was titrated in NMR tube with small aliquots of a concentrated solution of tetrabutylammonium chloride ( $70 \mathrm{mM}$ in $\mathrm{CDCl}_{3} / \mathrm{MeOD} 8: 2$ ). Complexation induced shifts $\Delta \delta$ of the phosphorus signal of the host were measured after each addition and plotted as a function of the guest/host ratio. Mathematical analysis of the data and graphic presentation of the results were performed using the HypNMR 2008 program [35], handling general host-guest association equilibria under fast exchange regime on the NMR time scale. This allows obtaining the binding constant $K a$.

\section{4. ${ }^{1} H$ NMR continuous variation method (Job's plot)}

Stock solutions ( $1 \mathrm{mM}$ in $\mathrm{CDCl}_{3} / \mathrm{MeOD} 8: 2$ ) of host 3iPO 2 and of $n$ - $\mathrm{Bu}_{4} \mathrm{NCl}$ were prepared and mixed in NMR tubes with different guest/host ratios. In this way, relative concentrations were varied continuously but their sum was kept constant $(1 \mathrm{mM})$. ${ }^{1} \mathrm{H}$ NMR spectra were recorded for each sample and chemical shifts of the aromatic protons in ortho- position of the phenolic $\mathrm{OH}$ groups were measured. Job plots were obtained by plotting $\Delta \delta \times \alpha=\left(\delta_{\text {obs }}-\delta_{\text {free }}\right) \times \alpha$ versus $\alpha$, where $\alpha$ is the host mole fraction defined as $\alpha=\frac{[3 \mathrm{PPO} 2]}{[3 \mathrm{PO} 2]+[\mathrm{ammonium}]}$ and $\delta_{\text {free }}$ is the chemical shift of the aromatic protons in the free host (Fig. S6, Supporting information) The stoichiometry of the complexes was obtained from the value of the mole fraction $\alpha$, which corresponds to a maximum of the curve: for a $1: 1$ complexation a $\alpha_{\max }$ value of 0.5 is expected whereas for a 2:1 host/guest complexation a $\alpha_{\max }$ value of 0.66 is foreseen. 


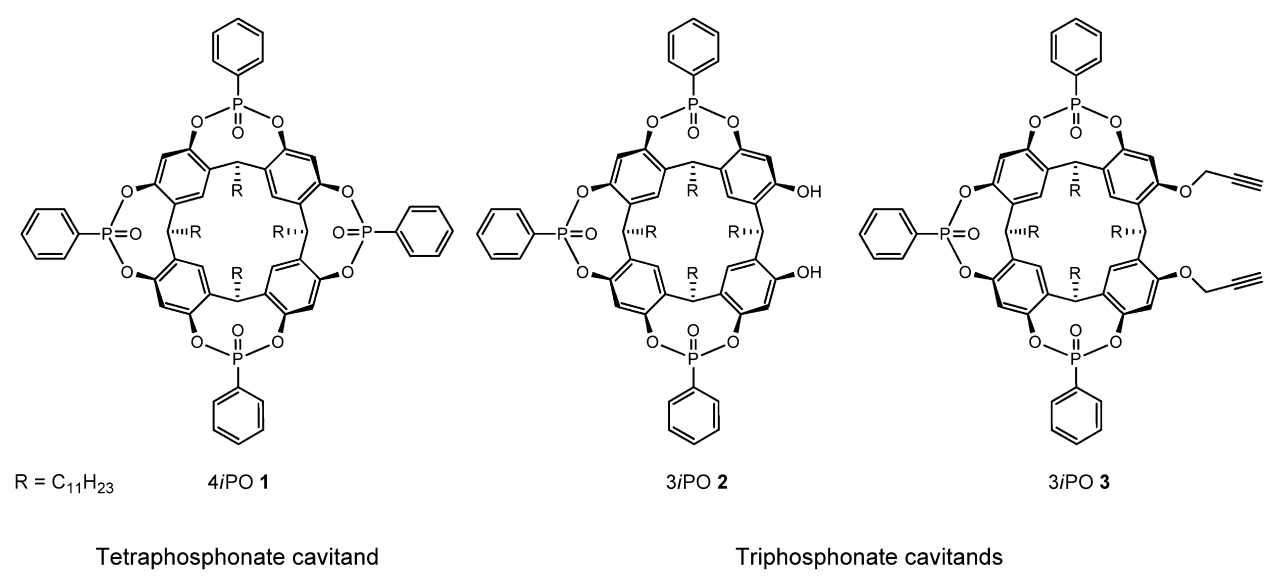

Fig. 1. Structures of cavitand hosts used in this study.

\subsection{Catalytic testing}

1,2-Epoxyhexane (2.0 mmol), $n$ - $\mathrm{Bu}_{4} \mathrm{NX}(\mathrm{X}=\mathrm{Cl}, \mathrm{I})(2 \mathrm{~mol} \%)$, cavitand host ( $2 \mathrm{~mol} \%), 2,4$-dibromomesitylene (used as internal standard) and methyl ethyl ketone (MEK, $2 \mathrm{~mL}$ ) were loaded into a $25 \mathrm{~mL}$ stainless autoclave. The reactor was flushed three times at room temperature with 10 bar of $\mathrm{CO}_{2}$ to remove air from the vessel before being further charged to $10 \mathrm{bar}$ of $\mathrm{CO}_{2}$ and raised to $80^{\circ} \mathrm{C}$. After the desired reaction time $(18 \mathrm{~h})$, the reactor was cooled to room temperature and then in an ice bath and finally the excess of $\mathrm{CO}_{2}$ was carefully released. Reaction yields were determined by ${ }^{1} \mathrm{H}$ NMR. A typical ${ }^{1} \mathrm{H}$ NMR trace of the crude reaction mixture is provided in Fig. S7 (Supporting information).

\section{Results and discussion}

\subsection{Synthesis and structural features of cavitands}

Three phosphonate cavitand hosts bearing C11 alkyl chains have been considered during the course of this study (Fig. 1). The 4iPO tetraphosphonate cavitand $\mathbf{1}$ was chosen for its strong binding properties arising from the optimized arrangement of the four $\mathrm{P}=\mathrm{O}$ groups oriented toward the cavity, which should provide optimal ammonium cation complexation. Two variations on this structure were prepared. In the 3iPO triphosphonate cavitand $\mathbf{2}$, one of the phosphonate groups was absent, leaving two phenolic hydroxyl groups in its place. This molecule was designed to have hostguest capability close to 4iPO 1 while introducing acidic phenol functionalities. The third in the series is the triphosphonate cavitand 3iPO 3 obtained by protecting the terminal $\mathrm{OH}$ groups in 3iPO 2 as propargyl ethers, thus removing the acidic functionality but closely mimicking the complexation properties of $\mathbf{2}$. Although weaker binding properties are expected for 3iPO 2 and 3, with respect to 4iPO $\mathbf{1}$, due to the lack of one PO group, investigating these three hosts will be of great importance to delineate clear structure-activity relationships.

Cavitand hosts 4iPO $\mathbf{1}$ and 3iPO 2 were synthesized following previous procedures developed by our group [33,34]. Host 1 was readily obtained in one step by reacting resorcin[4] arene, bearing four $\mathrm{C} 11$ alkyl chains, with $\mathrm{PhP}(\mathrm{O}) \mathrm{Cl}_{2}$ in the presence of $\mathrm{N}$-methylpyrrolidine. Host 2 required first the formation of the thiophosphonate derivative from resorcin[4]arene, $\mathrm{PhPCl}_{2}$ and sulfur, followed by subsequent oxidation with $m$ chloroperoxybenzoic acid. Protection of the two phenolic groups in 2 was achieved with propargyl bromide in the presence of $\mathrm{K}_{2} \mathrm{CO}_{3}$ in DMF affording 3 in 76\% yield (Scheme S1). Full characterization of this new cavitand by ${ }^{1} \mathrm{H},{ }^{13} \mathrm{C},{ }^{31} \mathrm{P}$ NMR and HRMS is provided in

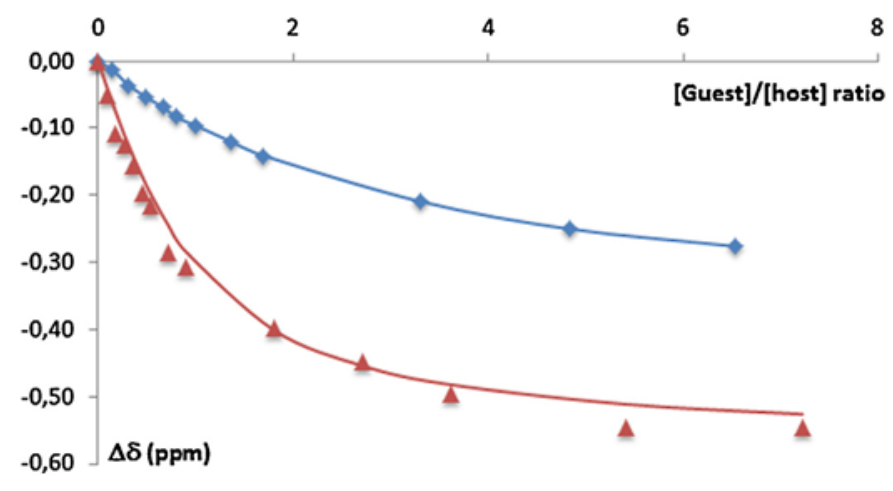

Fig. 2. ${ }^{31} \mathrm{P}$ NMR titration curves for the complexation of tetrabutylammonium chloride with $4 i P O \mathbf{1}(\mathbf{\Delta})$ and $3 i \mathrm{PO} \mathbf{2}(\bullet)$ ) hosts.

Experimental Section and Supporting information (Figs. S1-S3). In particular, the $C_{S}$ symmetry of $3 i \mathrm{PO} 3$ was identified by the presence of two ${ }^{31} \mathrm{P}$ resonances in a $1: 2$ ratio at 8.8 and $9.1 \mathrm{ppm}$ respectively in $\mathrm{CDCl}_{3}$ solution (Fig. S3).

\subsection{Binding studies}

Complexation studies between tetrabutylammonium cation and $4 i \mathrm{PO} 1$ and $3 i \mathrm{PO} 2$ hosts were investigated in $\mathrm{CDCl}_{3} / \mathrm{MeOD}$ solution (8:2) via ${ }^{31} \mathrm{P}$ NMR titrations (Fig. S4 and Table S1 for 4iPO 1 and Fig. S5 and Table S2 for 3iPO 2). For both cases, the binding constants $\mathrm{Ka}$ were determined through the complexation induced shifts $\Delta \delta$ of the phosphorus signal of the host measured after each addition of $n-\mathrm{Bu}_{4} \mathrm{NCl}$ and plotted as a function of the guest/host ratio (Fig. 2). In the case of the $n-\mathrm{Bu}_{4} \mathrm{NCl} / 4 i \mathrm{PO} 1$ host-guest system, the binding constant was found to be $18800 \mathrm{M}^{-2}$ whereas for $n-\mathrm{Bu}_{4} \mathrm{NCl} / 3 i \mathrm{PO} 2$ complex a significantly smaller association constant of $4380 \mathrm{M}^{-2}$ was obtained. This result is not surprising taken into account that the binding strength in phosphonate-based cavitands strongly depends on both the number and positioning of the $\mathrm{P}=\mathrm{O}$ groups at the upper rim of the molecule. In our case, all $\mathrm{P}=\mathrm{O}$ groups for both 4iPO 1 and 3iPO 2 hosts are oriented inward with respect to the cavity but the presence of only three $\mathrm{P}=\mathrm{O}$ binding sites in 3iPO 2 leads to a marked decrease of its affinity towards ammonium cation when compared to tetraphosphonate-bridged cavitand host. 


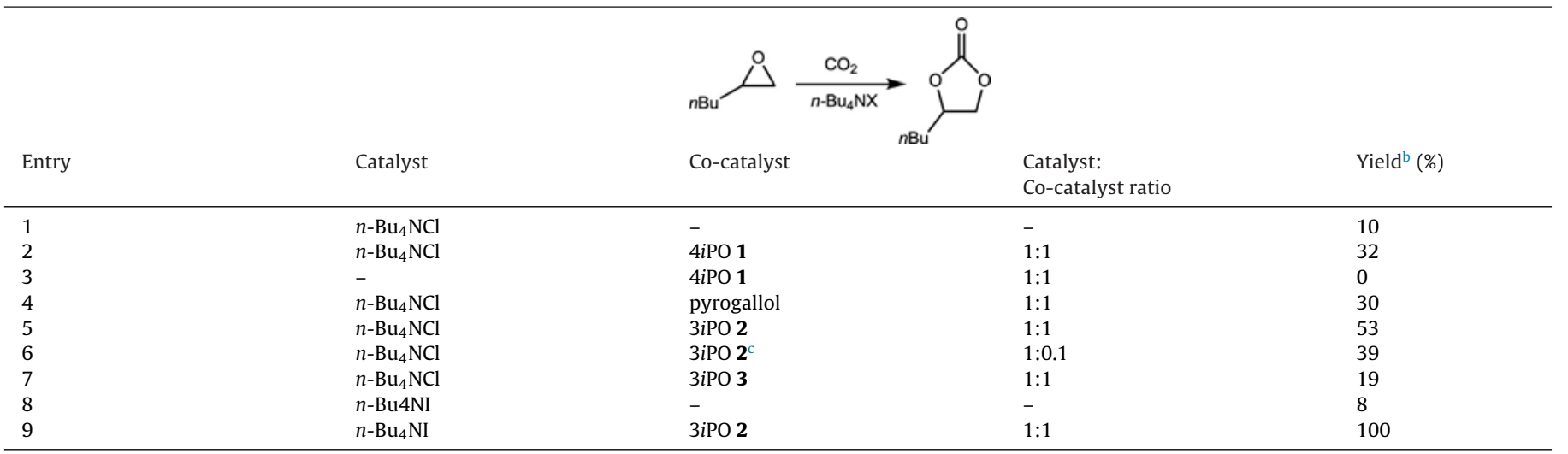

${ }^{a}$ Reaction conditions: 1,2-epoxyhexane ( $\left.2.0 \mathrm{mmol}\right), n$ - $\mathrm{Bu}_{4} \mathrm{NX}(2 \mathrm{~mol} \%)$, cavitand host $(2 \mathrm{~mol} \%), 80{ }^{\circ} \mathrm{C}, \mathrm{MEK}(2 \mathrm{~mL}), 10 \mathrm{bar} \mathrm{CO}_{2}$.

b Yields were determined at $18 \mathrm{~h}$ by ${ }^{1} \mathrm{H}$ NMR of the crude reaction mixture using 2,4-dibromomesitylene $(0.4 \mathrm{mmol})$ as an internal standard.

c $0.2 \mathrm{~mol} \%$ of 3 iPO 2 host.

\subsection{Coupling of $\mathrm{CO}_{2}$ and epoxides}

The influence of the cavitand hosts structure on catalytic performance has been investigated in detail using the coupling of 1,2-epoxyhexane with $\mathrm{CO}_{2}$ to produce hexene carbonate (EC) as a model reaction (Table 1 ). In a first series of experiments, the reaction was carried out in $\mathrm{MEK}$ using $n-\mathrm{Bu}_{4} \mathrm{NCl}$ as the principal catalyst component ( $2 \mathrm{~mol} \%$ ). Where used, co-catalysts were introduced in a 1:1 molar ratio with the ammonium salt. Under these reaction conditions, selectivity $\geq 99 \%$ was achieved for the carbonate product.

Under these conditions, in the absence of any co-catalyst, the reaction proceeds with very modest activity, yielding $10 \%$ hexene carbonate after $18 \mathrm{~h}$ at $80^{\circ} \mathrm{C}$ (entry 1 ). The addition of one equivalent of the cavitand 4iPO 1 leads to a marked increase in activity, producing a $32 \%$ yield (entry 2 ). Note that the reaction with $4 i \mathrm{PO} 1$ does not take place in the absence of $n-\mathrm{Bu}_{4} \mathrm{NCl}$ (entry 3 ). The use of the Brønsted acid pyrogallol (1,2,3-trihydroxybenzene), one of the best co-catalyst reported to date by the group of Kleij, leads to an increase in activity roughly equivalent to that observed with the cavitand $4 i P O 1$ (entry $4,30 \%$ yield).

Thus, one has two independent ways of enhancing catalysis: by liberating the halide for the initial ring-opening reaction with epoxide [32], and by activating the epoxide and/or stabilizing reaction intermediates through multiple hydrogen bonds [8,26,27]. As mentioned above, 3iPO 2 was prepared in order to have the possibility of these two modes of enhancement present in a single co-catalyst. As expected, 3iPO 2 proved to be very active, producing a 53\% yield under the standard conditions (entry 5 ). Even small quantities of 3iPO 2 had very strong effects on catalysis: using tentimes less co-catalyst $(0.2 \mathrm{~mol} \%)$ led to $39 \%$ yield after $18 \mathrm{~h}$ (entry 6 ), an activity even superior to that obtained with one equivalent of either $4 i$ PO 1 (32\% yield) or pyrogallol (30\% yield). The performance of 3iPO 3 should give some independent comparison of the effect of the varying cation complexation ability between $4 i \mathrm{PO} 1$ and 3iPO 2. The yield observed for 3iPO 3 was found to be $19 \%$ after $18 \mathrm{~h}$ (entry 7 ), which was significantly lower than the $32 \%$ yield obtained with 4iPO 1 (entry 2 ) and coherent with the lower binding affinity of triphosphonate-bridged cavitand hosts with respect to their tetraphosphonate counterparts. Furthermore, one can conclude that the acidic $\mathrm{OH}$ functional groups of 3iPO 2 have a predominant effect on catalyst enhancement, leading to the 53\% yield (entry 5) for that species. The potential of 3iPO 2 was also evaluated for iodide systems. The tetrabutyl ammonium iodide alone produced a $8 \%$ yield under the standard reaction con- ditions (entry 8) whereas the addition of one equivalent of 3iPO 2 to this catalyst led to quantitative yield after the same reaction period (entry 9), the most dramatic enhancement effect observed in this study. To further investigate the potential of the $n-\mathrm{Bu}_{4} \mathrm{NI} / 3 i \mathrm{PO} 2$ catalytic system, the reaction was conducted at shorter reaction time ( 3 and $6 \mathrm{~h}$ ) and the time dependent reaction profile has been displayed in Fig. S8 (Supporting information). After only $3 \mathrm{~h}$ of reaction, a $72 \%$ yield in hexene carbonate was already achieved (90\% yield in $6 \mathrm{~h}$ ) highlighting the remarkable capability of cavitand 3iPO 2 to promote the overall activity of ammonium-based catalyst system under mild reaction conditions.

\section{Conclusions}

In this work, we have demonstrated the high potential of host-guest systems to improve the catalytic properties of tetrabutylammonium halides in the coupling of $\mathrm{CO}_{2}$ with 1,2-epoxyhexane, affording the corresponding cyclic carbonate with enhanced yields. Two main factors have been investigated to rationalize our experimental results. First, we showed that the binding strength in the ammonium-cavitand association strongly correlates to the catalytic efficiency of the supramolecular systems. Comparing tetraand triphosphonate cavitand hosts showed that catalytic performance of $n-\mathrm{Bu}_{4} \mathrm{NCl}$ was greatly improved when associated to $4 i \mathrm{PO}$ 1 , a more powerful host for $n-\mathrm{Bu}_{4} \mathrm{~N}^{+}$cation, rather than to 3iPO 3 counterpart. In a second series of experiments, the participation of acidic functional groups within the cavitand structure was investigated using triphosphonate cavitands with and without acidic phenol functions, which had been reported to strongly interfere with the reaction. We observed that a double activation was possible with cavitand presenting hydroxyl functions in addition to complexation properties. Comparing cavitand 3iPO 2 bearing two phenolic groups with $3 i \mathrm{PO} 3$ where phenol functions were protected with alkyne substituents, we demonstrated the dramatic effect of the acidic functions on catalyst performance. Indeed, with $n-\mathrm{Bu}_{4} \mathrm{NCl} / 3 i \mathrm{PO} 2$ supramolecular system, both binding strength and activating $\mathrm{OH}$ groups act cooperatively to activate the epoxide substrate in a more efficient manner. Finally, the iodide salt was revealed to be the most efficient system when associated to 3iPO 2, emphasizing the interest of our new approach in the coupling of $\mathrm{CO}_{2}$ with epoxide. Current work is focused on making analogous heterogeneous systems to ensure easier catalyst recovery. 


\section{Acknowledgements}

We gratefully acknowledge financial support from the Région Rhône-Alpes, France (ARC environnement project).

\section{References}

[1] M. Aresta, Carbon Dioxide as Chemical Feedstock, Wiley-VCH Weinheim, 2010

[2] I. Omae, Catal. Today 115 (2006) 33-52.

[3] T. Sakakura, J.-C. Choi, H. Yasuda, Chem. Rev. 107 (2007) 2365-2387.

[4] M. Halmann, in: M. Halmann (Ed.) Chemical Fixation of Carbon Dioxide: Methods for Recycling CO $\mathrm{CO}_{2}$ into Useful Products, CRC Press, Boca Raton, 1993.

[5] P. Pescarmona, M. Taherimehr, Catal. Sci. Technol. 2 (2012) 2169-2187.

[6] C.J. Whiteoak, N. Kielland, V. Laserna, E.C. Escudero-Adan, E. Martin, A.W. Kleij, J. Am. Chem. Soc. 135 (2013) 1228-1231.

[7] J. Sun, L. Han, W. Cheng, J. Wang, X. Zhang, S. Zhang, ChemSusChem 4 (2011) 502-507.

[8] C.J. Whiteoak, A. Nova, F. Maseras, A.W. Kleij, ChemSusChem 5 (2012) 2032-2038.

[9] A.-A.G. Shaikh, S. Sivaram, Chem. Rev. 96 (1996) 951-976.

[10] B. Schäffner, F. Schäffner, S.P. Verevkin, A. Börner, Chem. Rev. 110 (2010) 4554-4581.

[11] D.J. Darensbourg, Chem. Rev. 107 (2007) 2388-2410.

[12] J.H. Clements, Ind. Eng. Chem. Res. 42 (2003) 663-674.

[13] M. North, R. Pasquale, C. Young, Green Chem. 12 (2010) 1514-1539.

[14] C.J. Whiteoak, A.W. Kleij, Synlett 24 (2013) 1748-1756.

[15] T. Ema, Y. Miyazaki, S. Koyama, Y. Yano, T. Sakai, Chem. Commun. 48 (2012) 4489-4491.
[16] A. Decortes, A.M. Castilla, A.W. Kleij, Angew. Chem. Int. Ed. 49 (2010) $9822-9837$

[17] C. Martin, G. Fiorani, A.W. Kleij, ACS Catal. 5 (2015) 1353-1370.

[18] J. Meléndez, M. North, R. Pasquale, Eur. J. Inorg. Chem. (2007) 3323-3326.

[19] C.J. Whiteoak, N. Kielland, V. Laserna, F. Castro-Gómez, E. Martin, E.C. Escuardo-Adán, C. Bo, A.W. Kleij, Chem. Eur. J. 20 (2014) 2264-22754

[20] M. North, R. Pasquale, Angew. Chem. Int. Ed. 48 (2009) 2946-2948.

[21] V. Calo, A. íNacci, A. Monopoli, A. Fanizzi, Org. Lett. 4 (2002) 2561-2563.

[22] Z.-Z. Yang, L.-N. He, C.-X. Miao, S. Chanfreau, Adv. Synth. Catal. 352 (2010) $2233-2240$.

[23] H. Kawanami, A. Sasaki, K. Matsui, Y. Ikushima, Chem. Commun. (2003) 896-897.

[24] Y. Tsutsumi, K. Yamakawa, M. Yoshida, T. Ema, T. Sakai, Org. Lett. 12 (2010) $5728-5731$

[25] Y.-M. Shen, W.-L. Duan, M. Shi, Adv. Synth. Catal. 345 (2003) 337-340.

[26] M.E. Wilhelm, M.H. Anthofer, M. Cokoja, I.I.E. Markovits, W.A. Herrmann, F.E Kühn, ChemSusChem 7 (2014) 1357-1360.

[27] Sergio Sopeňa, Giulia Fiorani, Carmen Martín, Arjan W. Kleij, ChemSusChem 8 (2015) 3248-3254.

[28] J. Sun, L. Han, W. Cheng, J. Wang, X. Zhang, S. Zhang, ChemSusChem 4 (2011) 502-507.

[29] B. Chatelet, E. Jeanneau, J.-P. Dutasta, V. Robert, A. Martinez, V. Dufaud, Catal. Commun. 52 (2014) 26-30.

[30] B. Chatelet, L. Joucla, J.-P. Dutasta, A. Martinez, V. Dufaud, Chem. Eur. J. 20 2014) 8571-8574.

[31] B. Chatelet, L. Joucla, J.-P. Dutasta, A. Martinez, K.C. Szeto, V. Dufaud, J. Am. Chem. Soc. 135 (2013) 5348-5351.

[32] A. Mirabaud, J.-C. Mulatier, A. Martinez, J.-P. Dutasta, V. Dufaud, ACS Catal. 5 (2015) 6748-6752.

[33] M. Melegari, M. Suman, L. Pirondini, D. Moiani, C. Massera, F. Ugozzoli, E. Kalenius, P. Vainiotalo, J.-C. Mulatier, J.-P. Dutasta, E. Dalcanale, Chem. Eur. J. 14 (2008) 5772-5779.

[34] B. Dubessy, S. Harthong, C. Aronica, D. Bouchu, M. Busi, E. Dalcanale, J.-P. Dutasta, J. Org. Chem. 74 (2009) 3923-3926.

[35] C. Frassineti, S. Ghelli, P. Gans, A. Sabatini, M.S. Moruzzi, A. Vacca, Anal. Biochem. 231 (1995) 374-382. 